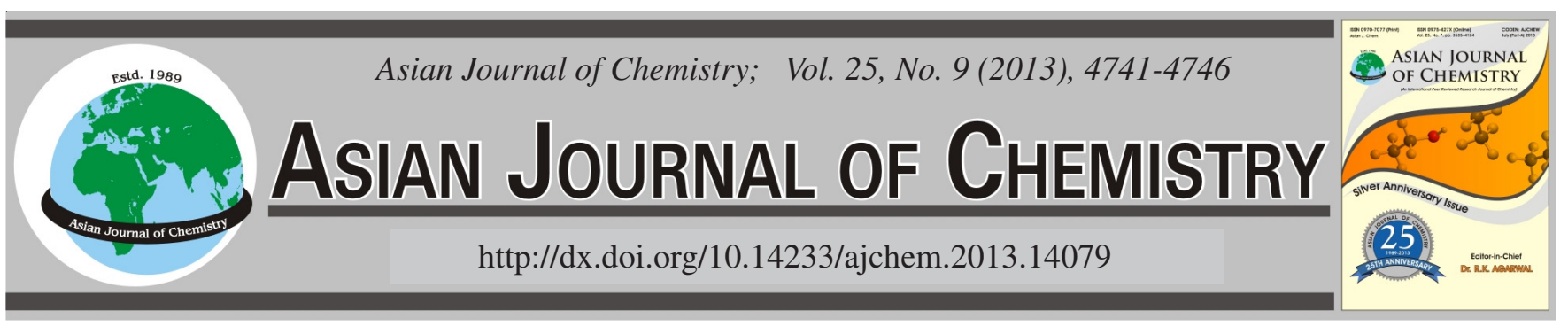

\title{
Chemical Composition of the Essential Oil from Nepeta macrosiphon Boiss. Growing Wild in Iran by Different Extraction Methods and Studies on the Quantitative Relationship Between the Retention Indices of Essential Oils and their Molecular Structures
}

\author{
Parviz Aberoomand Azar ${ }^{1}$, Karim Zare ${ }^{1}$, Mohammad Saber-Tehrani ${ }^{1}$, Azizolah Jafari Kokhedan ${ }^{2}$, \\ Azam VAfael $^{1, *}$, Mehdi Nekoei ${ }^{3}$ and Kambiz LariJani ${ }^{1}$
}

\begin{abstract}
${ }^{1}$ Department of Chemistry, Science and Research Branch, Islamic Azad University, Tehran, Iran
${ }^{2}$ Department of Biology, Basic Science Faculty, University of Yasouj, Yasouj, Iran

${ }^{3}$ Department of Chemistry, Shahrood Branch, Islamic Azad University, Shahrood, Iran

*Corresponding author: E-mail: a.vafaei11@yahoo.com
\end{abstract}

(Received: 21 May 2012;

Accepted: 4 March 2013)

AJC-13061

Hydrodistillation, solvent free microwave extraction and solid phase microextraction methods has been applied to extraction of essential
oil from Nepeta macrosiphon growing in Iran. Spathulenol $(28.8,32.28$ and 7.68$)$ and $\beta$-caryophyllene $(9.6,5.83$ and 15.19$)$ were the
main compounds in the essential oil, respectively. High amount of sesquiterpenes and low quantity of hydrocarbon monoterpenes were
identified in the essential oils. Then a simple, strong, descriptive and interpretable model, based on a quantitative structure-retention
relationship is developed using stepwise multiple linear regression (SW-MLR) approach for prediction of the retention index (RI) of |
Nepeta macrosiphon essential oil. A model with low prediction error $(2.071 \%)$ and good coefficient of determination $(0.982)$ was
obtained. This model was used for the prediction of the RI values of some essential oil components which were not used in the modeling
procedure.

Key Words: Nepeta macrosiphon, Spathulenol, Quantitative structure-retention relationship, Stepwise multiple linear regression.

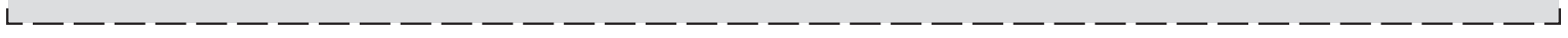

\section{INTRODUCTION}

Essential oils are isolated from different sections of plants such as flowers, seeds, leaves, stems and roots. Essential oil are applied extensively in the perfume, cosmetic, foods, beverages and confectioneries and as ingredients of disinfectants and insecticides ${ }^{1}$. Essential oil can be separated using some isolation methods, such as hydrodistillation (HD), steam distillation (SD), solid phase micro extraction (SPME), ultrasonic extraction (US), microwave assisted distillation (MAD) and solvent free microwave extraction (SFME). Hydrodistillation has been typical method to extract the essential oils from herbal plants. Nevertheless, in order to decrease operation time, costs and solvent depletion, to obtain higher yields and purity and also to improve the quality of the extracts, new methods namely, microwave-assisted extraction, supercritical fluid extraction and solvent free microwave extraction have been utilized ${ }^{2}$.

Solid phase micro extraction is sample preparation methods in this method extraction and sample preparation are carried out into one step. Solid phase micro extraction utilizes a fused silica fiber coated with a liquid (polymer) or a solid (sorbent).
The coated fiber is submerged into an aqueous solution sample or the headspace above the sample. Analytes are extracted by fiber after extraction, analytes are desorbed from the coated fiber to a chromatography column. Solid phase micro extraction has some advantages such as solvent less,fast sampling, low cost and sensitivity ${ }^{3}$.

Microwave extraction is research field in modern chemistry. Microwave-assisted extraction is appropriate alternative to conventional techniques. The basic advantages of using microwave energy are decrease of extraction time and cost, faster energy transfer and deletion of process steps. Solvent free microwave extraction is carried out at atmospheric pressure and no need to add any water and solvent. In this method, herbal plant is put in microwave reactor the internal heating of in situ water within fresh plant swells it and result in the gland and oleiferous receptacles fracture. Therefore essential oil is released and evaporated by the in situ water. The distillate condensed by the external cooling system ${ }^{4,5}$.

The genus Nepeta (Lamiaceae) with the common Persian name of pune-say comprises about 280 species in the world and 67 species that are found all over of Iran 6 . Some species are applied in folk medicine as a fortifier, disinfectant, bacteriostatic 
and treating eczema type disorders ${ }^{7,8}$. Nepeta macrosiphon Boiss distributed in various rocky western areas of $\operatorname{Iran}^{7}$. The Persian names of the plant are "punesay-e-sisakhti" and "punesay-elulehboland"6. Chemical composition of the essential oil of Nepeta macrosiphon has been studided ${ }^{10,11}$. In this work, analysis of the essential oil compounds of Nepeta macrosiphon were performed by GC and GC-MS equipment. The essential oil was achieved with hydro distillation (HD), solid phase micro extraction (SPME) and solvent free microwave extraction (SFME) methods.

Nowadays much interest is devoted to the prediction of physicochemical properties of molecules, such as their biological activity, chemical property, or their retention on chromatographic systems, etc. This is usually accomplished by implementing so-called quantitative structure-property relationship (QSPR) models, which relate the property of interest, with a set of molecular descriptors.Quantitative structure-retention relationships (QSRR) have also been used to obtain simple models to explain and predict the chromatographic behaviour of various classes of compounds ${ }^{12-18}$. Quantitative structure-retention relationships are statistical models which quantify the relationship between the structure of a molecule and its chromatographic retention index, enabling prediction of the retention indices of novel compounds.

Application of these techniques usually requires selection of variables to build well-fitting models. In this work we used the stepwise method for variable selection in multiple linear regression.

The aim of this work is analysis of the essential oil compounds of Nepeta macrosiphonand to search for an efficient method to build an accurate quantitative relationship between the molecular structure and the retention indices of the Nepeta macrosiphonessential oils by stepwise-multiple linear regression.

\section{EXPERIMENTAL}

Plant material: Nepeta macrosiphonwas collected in May 2010, from the Dena Mountain in Kohgiluyeh and Boyerahmad Province.

Gas chromatography: Analytical GC was carried out on a Shimadzu 15A gas chromatography equipped with a split/ splitless injector $\left(250{ }^{\circ} \mathrm{C}\right)$ and a flame ionization detector $\left(250{ }^{\circ} \mathrm{C}\right)$. DB-5 capillary column $(30 \mathrm{~m} \times 0.25 \mathrm{~mm}$, film thickness $0.32 \mu \mathrm{m})$ and type of carrier gas was $\mathrm{N}_{2}(1 \mathrm{~mL} / \mathrm{min})$. The column temperature was held at $60{ }^{\circ} \mathrm{C}$ for $3 \mathrm{~min}$ and then heated to $250{ }^{\circ} \mathrm{C}$ with a $6{ }^{\circ} \mathrm{C} / \mathrm{min}$ rate and held constant at $250{ }^{\circ} \mathrm{C}$ for $5 \mathrm{~min}$.

Gas chromatography-mass spectrometry: GC-MS analyses were accomplished by Hewlett-Packard (HP-6890/ 5973) GC-MC system coupled with an HP-5MS column(30 $\mathrm{m} \times 0.25 \mathrm{~mm}$, film thickness $0.32 \mu \mathrm{m})$. The column temperature was as like as GC condition. Helium was used as carrier gas $(1 \mathrm{~mL} / \mathrm{min})$ beside ionization energy in MS was $70 \mathrm{eV}$, mass range 40-300 amuand scan time was $1 \mathrm{~s}$.

\section{Isolation methods}

Hydrodistillation: Dried aerial part of Nepeta macrosiphon $(100 \mathrm{~g})$ were submitted to hydro distillation with a Clevengertype apparatus for $4 \mathrm{~h}$ and the oils were dried under anhydrous sodium sulphate and kept in $4{ }^{\circ} \mathrm{C}$ until analyzed.
Solvent free microwave extraction (SFME): A Milestone Microsynth microwave apparatus, $2450 \mathrm{MHz}$ and ACTE0 sensor was applied. The maximum power was $1000 \mathrm{~W}$. The air-dried of Nepeta macrosiphon (35 g) was immersed in $25 \mathrm{~mL}$ distilled water for $1 \mathrm{~h}$ due to hydrate of the plant. The moistened plant was heated by an optimize power $800 \mathrm{w}$ and time $25 \mathrm{~min}$. The extracted oils were dried with anhydrous sodium sulphate and stored in $4{ }^{\circ} \mathrm{C}$ until analyzed.

Head space solid phase micro extraction (HS-SPME): $1.5 \mathrm{~g}$ of different parts (flower, leave and stem) of powdered sample was placed in $20 \mathrm{~mL}$ SPME vial sealed with PTFE septum caps from supelco (Bellefonte, USA). The vial was heated at $70{ }^{\circ} \mathrm{C}$ for $15 \mathrm{~min}$ then a $65 \mu \mathrm{m}$ polydimethylsiloxnedivinylbenzene (PDMS-DVB) fiber (supelco, USA) was subjected to head space of sample for $15 \mathrm{~min}$. Analytes desorption was performed at $250{ }^{\circ} \mathrm{C}$ for $3 \mathrm{~min}$ in a splitless GC injector.

Components identification: Identification of components was performed by comparison of their MS spectra and GC retention indices with those of authentic references ${ }^{19}$ and Wiley 257 mass spectra database. The retention indices were figured out using homologous series of normal alkanes.

Molecular descriptors: Molecular descriptors are defined as numerical characteristics associated with chemical structures. The molecular descriptor is the final result of a logic and mathematical procedure which transforms chemical information encoded within a symbolic representation of a molecule into a useful number applied to correlate physical properties.

The Dragon software was used to calculate the descriptors in this research and a total of 1481 molecular descriptors, from 18 different types of theoretical descriptor, were calculated for each molecule. Since the values of many descriptors are related to the bonds length and bonds angles etc., the chemical structure of every molecule must be optimized before calculating its molecular descriptors. For this reason, chemical structure of the 54 studied molecules were drawn with the Hyperchem software and saved with the HIN extension. To optimize the geometry of these molecules, the AM1 geometrical optimization was applied. After optimizing the chemical structures of all compounds, the molecular descriptors were calculated using Dragon. A wide variety of descriptors have been reported in the literature, having been used in the QSRR analysis ${ }^{20-25}$.

\section{RESULTS AND DISCUSSION}

The percentage composition of essential oil from Nepeta macrosiphon with three isolation methods is shown in Table-1.

Spathulenol (28.8, 32.28 and 7.68) and $\beta$-caryophyllene (9.6, 5.83 and 15.19) were the main compounds in the essential oil of Nepeta macrosiphon that achieved by hydrodistillation, solvent free microwave extraction and headspace-solid phase micro extraction, respectively.

The oils were obtained by these methods has high amount of sesquiterpenes and low quantity of hydrocarbon monoterpenes. Comparing these results with previous studies on oil of Nepeta macrosiphon demonstrated that they were also predominated by sesquiterpenes.

Fig. 1 showed that the essential oil obtained by SFME method has higher quantity of oxygenated compounds and 


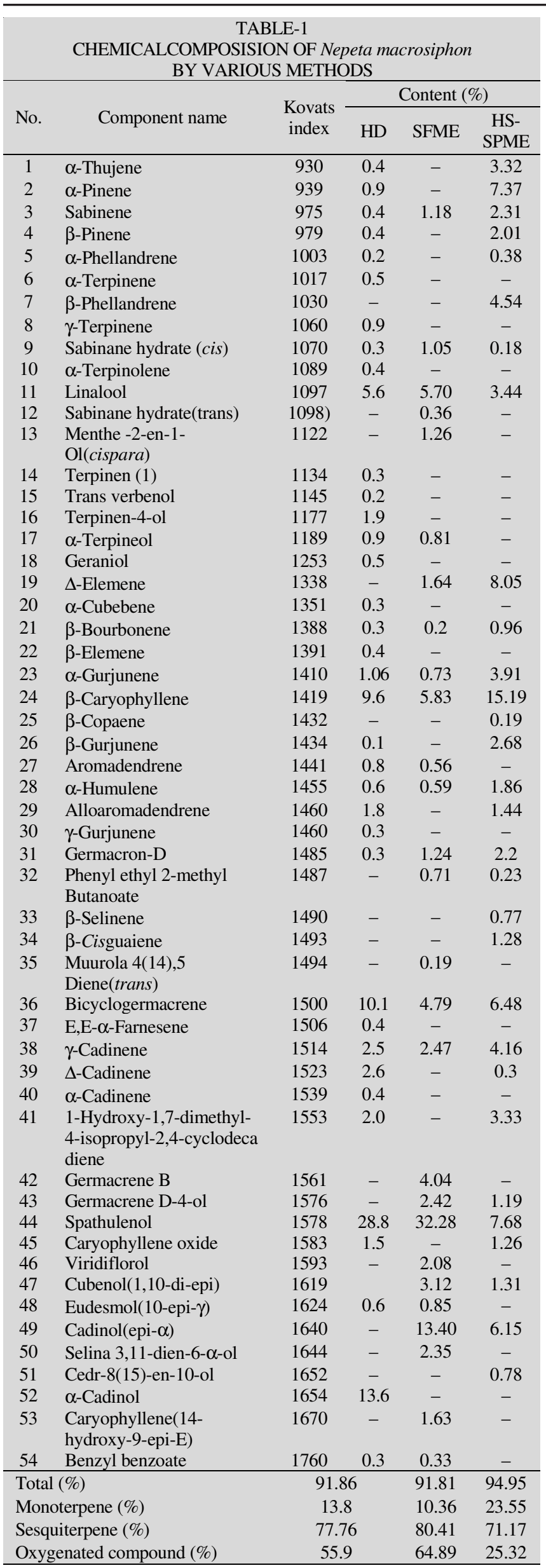

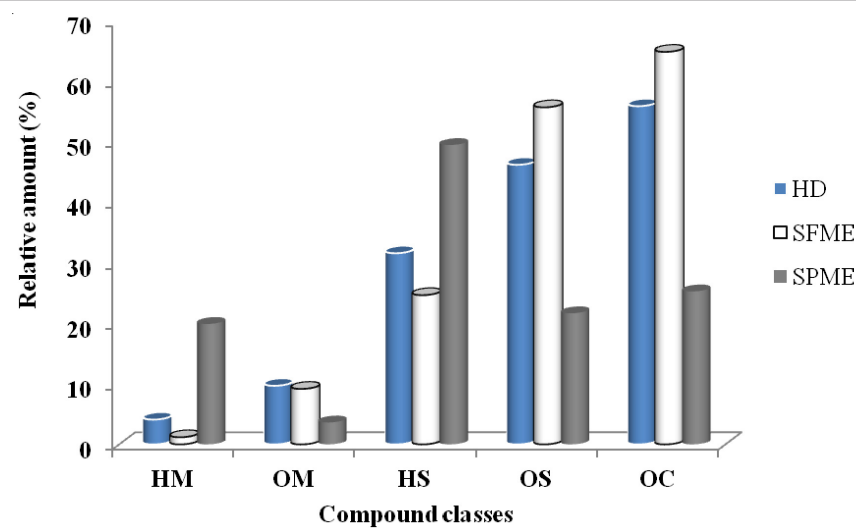

Fig. 1. Comparison of relative amount of different compounds classes by various methods

lower amount of monoterpenes hydrocarbons than the essential oil extracted by HD method. Solvent free microwave extraction uses rapid heating of polar solvent (water), smaller quantity of water, time and energy consuming compared with traditional HD method which leads to reduction in decomposition of oxygenated compounds by thermal and hydrolytic effects ${ }^{26}$.

Theoretical results: A stepwise multiple linear regression procedure was used for variable selection. This method has been used for variable selection or model development in variety systems $\mathrm{s}^{27,28}$. For regression analysis, data set was separated into two groups: training and prediction sets. The molecules included in these sets were selected randomly. The training set, consisted of 43 molecules, was used for the model generation using the SPSS software package. The prediction set, consisted of 11 molecules, was used to evaluate the generated model. It is clear that many multiple linear regression models will result using stepwise multiple regression procedure; among them we have to choose the best one. It is common to consider four statistical parameters for this purpose. These parameters are the number of descriptors, coefficient of determination $\left(\mathrm{R}^{2}\right)$ for training and prediction sets, standard error (SE) for training and prediction sets and F statistic. A reliable multiple linear regression model is one that has high $\mathrm{R}^{2}$ and $\mathrm{F}$ values, low $\mathrm{SE}$ and least number of descriptors. In addition to these, the model should have a high predictive ability. Consequently, among different models, the best model was chosen, whose specifications are presented in Table-2. It is obvious that as the number of descriptors increase the $\mathrm{R}^{2}$ will increase. Fig. 2 shows the effect of increasing the number of descriptors on $\mathrm{R}^{2}$ values. It can be seen from this figure that increasing the number of parameters only up to seven has a large influence on improving correlation. Therefore, we have chosen seven descriptors as optimum number of parameters. The descriptors appearing in this model and definitions are given in Table-2. Dragon software can easily calculate these descriptors and their equations are not given here for the sake of brevity ${ }^{1}$. As it can be seen from the correlation matrix (Table-3) there is no significant correlation between the selected descriptors.

The data set and the corresponding experimental and predicted RI values of all the molecules studied in this work are summarized in Table-4. Fig. 3 shows a plot of values predicted by the SW-MLR against experimental values of the retention indices of the training and prediction sets. The residuals 
TABLE-2

SELECTED DESCRIPTORS OF MULTIPLE LINEAR REGRESSION

\begin{tabular}{|c|c|c|c|}
\hline Descriptor & Type of descriptor & Notation & Coefficient \\
\hline Modified Randic chi-1 index & Topological & XMOD & 29.004 \\
\hline Moran autocorrelation-lag $1 /$ weighted by atomic Sanderson electronegativities & 2D autocorrelations & MATS1e & -953.683 \\
\hline Mean topological charge index of order1 & Galvez topol.charge indices & JGI1 & -454.513 \\
\hline The symbol C-002 corresponds to: $\mathrm{CH}_{2} \mathrm{R}_{2}$ & Atom-centred fragments & C-002 & 23.307 \\
\hline $\mathrm{H}$ autocorrelation of lag 7/weighted by atomic masses & GETAWAY & $\mathrm{H} 7 \mathrm{~m}$ & -1402.278 \\
\hline Distance/detour ring index of order 6 & Topological & D/Dr06 & 0.589 \\
\hline $2^{\text {nd }}$ component accessibility directional WHIM index/ weighted by atomic masses & WHIM & $\mathrm{E} 2 \mathrm{~m}$ & 348.373 \\
\hline Constant & - & - & 231.432 \\
\hline
\end{tabular}

\begin{tabular}{|c|c|c|c|c|c|c|c|}
\hline \multicolumn{8}{|c|}{$\begin{array}{c}\text { TABLE-3 } \\
\text { CORRELATION MATRIX FOR THE FOUI }\end{array}$} \\
\hline & MATS1e & JGI1 & C-002 & $\mathrm{H} 7 \mathrm{~m}$ & D/Dr06 & $\mathrm{E} 2 \mathrm{~m}$ & MATS1e \\
\hline MATS1e & 1 & - & - & - & - & - & - \\
\hline JGI1 & 0.115 & 1 & - & - & - & - & - \\
\hline C-002 & -0.365 & -0.419 & 1 & - & - & - & - \\
\hline $\mathrm{H} 7 \mathrm{~m}$ & 0.559 & 0.189 & 0.021 & 1 & - & - & - \\
\hline D/Dr06 & 0.492 & -0.071 & -0.187 & 0.191 & 1 & - & - \\
\hline $\mathrm{E} 2 \mathrm{~m}$ & 0.048 & 0.062 & -0.137 & -0.184 & 0.129 & 1 & - \\
\hline MATS1e & 0.654 & 0.058 & -0.283 & 0.333 & 0.231 & -0.112 & 1 \\
\hline
\end{tabular}

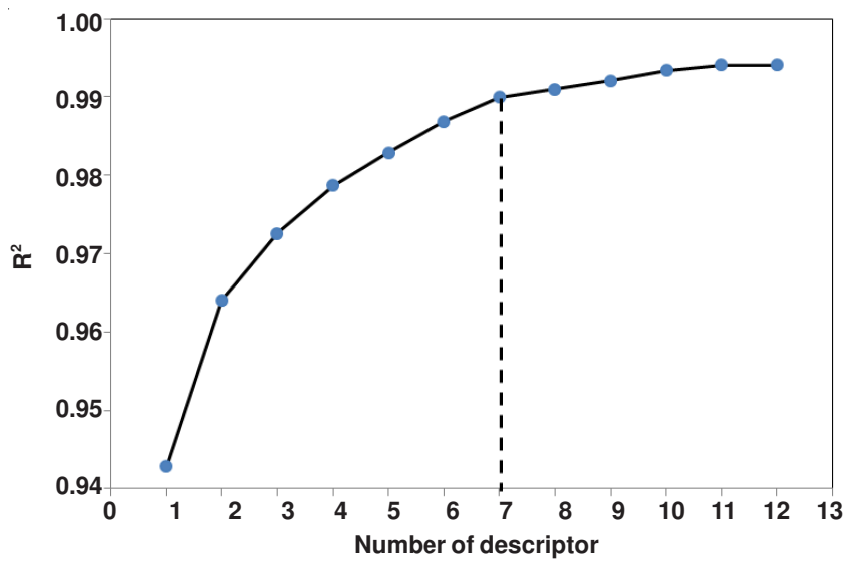

Fig. 2. Influence of number of descriptors on $\mathrm{R}^{2}$ of MLR model

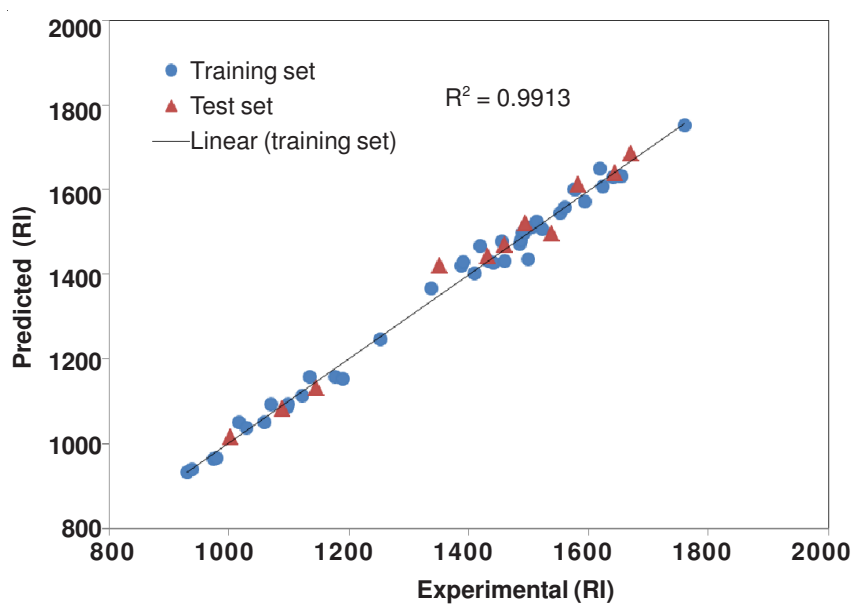

Fig. 3. Predicted RI values by the MLR modeling vs. the experimental retention index (RI) values

experimental RI-predicted RI) versus experimental RI value, obtained by the SW-MLR modeling, shown in Fig. 4. The distribution of the residuals on both sides of the zero line indicates there is no systematic error in the SW-MLR model.

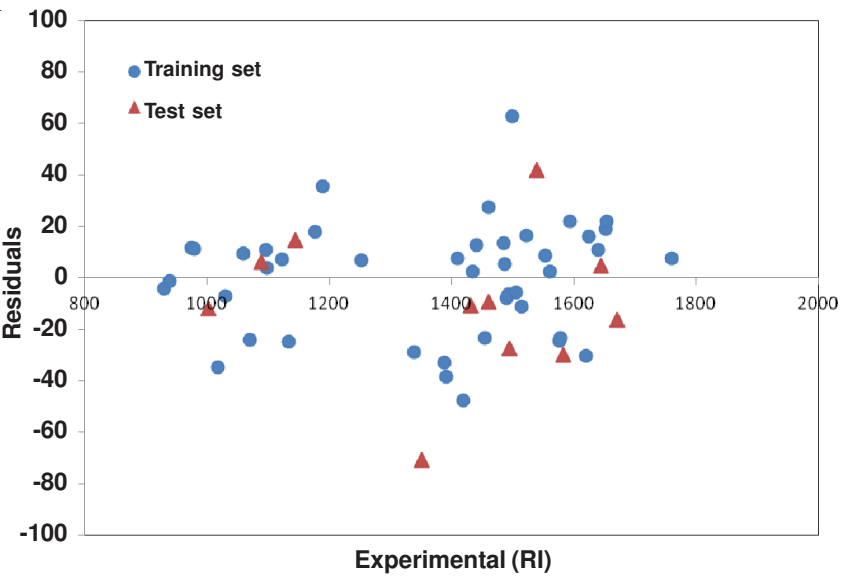

Fig. 4. Plot of the residuals against the experimental values of the retention indices

Statistical parameters: For evaluation of the predictive power of the generated MLR, the optimized model was applied for prediction of RI values of test compounds in the prediction set, which were not used in the optimization procedure. For the constructed models, two general statistical parameters were selected to evaluate the prediction ability of the model for RI. For this case, the predicted RI of each sample in prediction step was compared with the experimental RI.

Root mean square error of prediction (RMSEP) is a measurement of the average difference between predicted and experimental values, at the prediction stage. RMSEP can be interpreted as the average prediction error, expressed in the same units as the original response values. The RMSEP was obtained by the following formula:

$$
\operatorname{RMSEP}=\left[\frac{1}{2} \sum_{\mathrm{i}=1}^{\mathrm{n}}\left(\mathrm{y}_{\mathrm{i}}-\hat{\mathrm{y}}_{\mathrm{i}}\right)^{2}\right]^{0.5}
$$

The second statistical parameter was relative error of prediction (REP) that shows the predictive ability of each component and is calculated as 


\begin{tabular}{|c|c|c|c|c|}
\hline \multicolumn{5}{|c|}{$\begin{array}{c}\text { TABLE-4 } \\
\text { DATA SET AND THE CORRESPONDING OBSERVED AND } \\
\text { PREDICTED RETENTION INDEX (RI) VALUES BY } \\
\text { SW-MLR FOR THE TRAINING AND TEST SET }\end{array}$} \\
\hline No. & Compound & $\begin{array}{c}\mathrm{RI} \\
(\exp )^{\mathrm{a}}\end{array}$ & $\begin{array}{l}\text { RI (SW- } \\
\text { MLR) }^{\text {b }}\end{array}$ & $\begin{array}{c}\mathrm{E} \\
(\%)^{\mathrm{c}}\end{array}$ \\
\hline \multicolumn{5}{|c|}{ Training set } \\
\hline 1 & $\alpha$-Thujene & 930 & 934.17 & 0.45 \\
\hline 2 & $\alpha$-Pinene & 939 & 939.98 & 0.10 \\
\hline 3 & Sabinene & 975 & 963.40 & -1.19 \\
\hline 4 & $\beta$-Pinene & 979 & 967.47 & -1.18 \\
\hline 5 & $\alpha$-Terpipinene & 1017 & 1051.76 & 3.42 \\
\hline 6 & $\beta$-Phellandrene & 1030 & 1037.13 & 0.69 \\
\hline 7 & $\gamma$-Terpinene & 1060 & 1050.37 & -0.91 \\
\hline 8 & cis-Sabinene hydrate & 1070 & 1093.84 & 2.23 \\
\hline 9 & Linalool & 1097 & 1085.95 & -1.01 \\
\hline 10 & trans-Sabinene hydrate & 1098 & 1093.84 & -0.38 \\
\hline 11 & Menthe-2-en-1-ol & 1122 & 1114.56 & -0.66 \\
\hline 12 & Terpinene -1 & 1134 & 1158.58 & 2.17 \\
\hline 13 & Terpinene-4-ol & 1177 & 1159.01 & -1.53 \\
\hline 14 & $\alpha$-Terpineol & 1189 & 1153.34 & -3.00 \\
\hline 15 & Geraniol & 1253 & 1246.10 & -0.55 \\
\hline 16 & $\delta$-Elemene & 1338 & 1366.67 & 2.14 \\
\hline 17 & $\beta$-Bourbonene & 1388 & 1420.65 & 2.35 \\
\hline 18 & $\beta$-Elemene & 1391 & 1429.25 & 2.75 \\
\hline 19 & $\alpha$-Gurjunene & 1410 & 1402.35 & -0.54 \\
\hline 20 & $\beta$-Caryophyllene & 1419 & 1466.50 & 3.35 \\
\hline 21 & $\beta$-Gurjunene & 1434 & 1431.43 & -0.18 \\
\hline 22 & Aromadendrene & 1441 & 1428.23 & -0.89 \\
\hline 23 & $\alpha$-Humulene & 1455 & 1478.09 & 1.59 \\
\hline 24 & Alloaromadendrene & 1460 & 1432.41 & -1.89 \\
\hline 25 & Germacron-D & 1485 & 1471.25 & -0.93 \\
\hline 26 & Phenylethyl2-methylbutanoate & 1487 & 1481.64 & -0.36 \\
\hline 27 & $\beta$-Selinene & 1490 & 1497.76 & 0.52 \\
\hline 28 & $\beta$-cis-Guainene & 1493 & 1499.35 & 0.43 \\
\hline 29 & Bicyclogermacrene & 1500 & 1437.28 & -4.18 \\
\hline 30 & E,E- $\alpha$-Farnesene & 1506 & 1511.66 & 0.38 \\
\hline 31 & $\gamma$-Cadinene & 1514 & 1524.91 & 0.72 \\
\hline 32 & $\delta$-Cadinene & 1523 & 1506.41 & -1.09 \\
\hline 33 & $\begin{array}{l}\text { 1-Hydroxy-1,7-dimethyl-4- } \\
\text { isopropyl-2,4-cyclodecadiene }\end{array}$ & 1553 & 1544.26 & -0.56 \\
\hline 34 & Germacrene B & 1561 & 1558.39 & -0.17 \\
\hline 35 & Germacrene D-4-ol & 1576 & 1600.41 & 1.55 \\
\hline 36 & Spathulenol & 1578 & 1601.40 & 1.48 \\
\hline 37 & Viridiflorol & 1593 & 1571.04 & -1.38 \\
\hline 38 & Cubenol(1,10-di-epi) & 1619 & 1649.25 & 1.87 \\
\hline 39 & $\gamma$-Eudesmol(10-epi) & 1624 & 1607.81 & -1.00 \\
\hline 40 & $\alpha$-Cadinol(epi) & 1640 & 1628.88 & -0.68 \\
\hline 41 & Cedr-8(15)-en-10-ol & 1652 & 1633.04 & -1.15 \\
\hline 42 & $\alpha$-Cadinl & 1654 & 1632.00 & -1.33 \\
\hline 43 & Benzyl benzoate & 1760 & 1752.18 & -0.44 \\
\hline \multicolumn{5}{|c|}{ Test set } \\
\hline 1 & $\alpha$-Phellandrene & 1003 & 1014.87 & 1.18 \\
\hline 2 & - & 1089 & 1082.74 & -0.58 \\
\hline 3 & trans-Verbenol & 1145 & 1130.49 & -1.27 \\
\hline 4 & $\alpha$-Cubebene & 1351 & 1421.57 & 5.22 \\
\hline 5 & $\beta$-Copaene & 1432 & 1442.84 & 0.76 \\
\hline 6 & $\gamma$-Gurjunene & 1460 & 1469.41 & 0.64 \\
\hline 7 & Muurola 4(14),5dien(trans) & 1494 & 1521.38 & 1.83 \\
\hline 8 & Alphcadinene & 1539 & 1497.07 & -2.72 \\
\hline 9 & Caryophyllene oxide & 1583 & 1612.94 & 1.89 \\
\hline 10 & Selina 3,11-dien-6-alpha-ol & 1644 & 1639.24 & -0.29 \\
\hline 11 & $\begin{array}{l}\text { Caryophyllene (14-hydroxy-9- } \\
\text { epi-E) }\end{array}$ & 1670 & 1686.06 & 0.96 \\
\hline
\end{tabular}

${ }^{a}$ Experimental retention index. ${ }^{\mathrm{b}}$ Stepwise multiple linear regression retention index. ${ }^{\mathrm{C}}$ Relative error.

$$
\operatorname{REP}(\%)=\frac{100}{\bar{y}}\left[\frac{1}{\mathrm{n}} \sum_{\mathrm{i}=1}^{\mathrm{n}}\left(\hat{\mathrm{y}}_{\mathrm{i}}-\mathrm{y}_{\mathrm{i}}\right)^{2}\right]^{0.5}
$$

where $y_{i}$ is the experimental RI of the essential oil in the sample $i, \hat{y}_{i}$ represents the predicted RI of the essential oil in the sample $i, \hat{y}$, is the mean of experimental RI in the prediction set and $\mathrm{n}$ is the total number of samples used in the prediction set. The statistical parameters calculated for the SW-MLR model are listed in under Table-2.

Also the model obtained was validated using leave-oneout (LOO) and leave-group-out (LGO) cross-validation process. For LOO cross-validation, a data point is removed from the set and the model is recalculated. The predicted property for that point is then compared with its actual value. This is repeated until each data point is omitted once. For LGO, $20 \%$ of the data points are removed from the dataset and the model is refitted, the predicted values for those points are then compared with its experimental values. Again, this is repeated until each data point has been omitted once. The cross-validation correlation coefficient $\left(\mathrm{Q}^{2}\right)$ is 0.986 for $\mathrm{LGO}$ and 0.988 for LOO. This confirms that the obtained regression model has a good internal and external-predictive power.

\section{Conclusion}

In this study, the essential oil of Nepeta macrosiphon was extracted by hydro distillation (HD), solvent free microwave extraction (SFME) and solid phase micro extraction (SPME) methods. Fifty four compounds were identified by mass spectrometry. The essential oil obtained by SFME method has higher content of oxygenated compounds and smaller amount of monoterpenes hydrocarbons than the essential oil extracted by HD method. The oxygenated compounds are very odoriferous and more important than monoterpenes hydrocarbons. Compared to many extraction methods SFME is simple, fast, green and solvent free for extraction of essential oil from material plants. Simple QSRR model was presented for prediction RI of the essential oils. This model is a multivariate linear model, which has seven variables (molecular descriptors). These seven molecular descriptors were selected using SW-MLR technique. These variables are calculated based on the chemical structure molecules. The QSRR model with simply calculated molecular descriptors could be employed to estimate the retention index for new compounds, even in the absence of the standard candidates.

\section{REFERENCES}

1. M.H. Boelens, Perfum. Flavor., 9, 1 (1985).

2. M.T. Golmakani and K. Rezaei, Food Chem., 109, 925 (2008).

3. J.A. Ruiz, J. Quilez, M. Mestres and J. Guasch, Cereal Chem., 3, 80 (2003).

4. M.E. Lucchesi, F. Chemat and J. Smadja, J. Chromatogr. A, 1043, 323 (2004).

5. M.E. Lucchesi, J. Smadja, S. Bradshaw, W. Louw and F. Chemat, J. Food Eng., 79, 1079 (2007).

6. V. Mozaffarian, A Dictionary of Iranian Plant Names. Farhang Moaser, Tehran, p. 360 (1996).

7. A. Rustaiyan and K. Nadji, Flavour Fragr. J., 14, 35 (1999).

8. K.M. Prir and R.D. Wygloszonesamp, Chem. Abstr., 78, 140368 (1973).

9. K.H. Rechinger, FloraIranica, AkademischeDruck-u, Verlagsanstalt, Gra, p. 108 (1982). 
10. K. Javidnia, R. Miri, A. Jafari and H. Rrezaei, Flavour Fragr. J., 19, 156 (2004).

11. A. Ghannadi, F. Aghazari, M. Mehrabani, A. Mohagheghzadeh and I. Mehregan, Iran J. Pharm. Res., 2, 103 (2003).

12. R. Todeschini and V. Consonni, Handbook of Molecular Descriptors; Wiley-VCH: Weinheim (2000)

13. R. Kaliszan, Chem. Rev., 107, 3212 (2007).

14. R. Elizabeth, W. Tong and W.J. Welsh, J. Liq. Chromatogr. Rel. Technol., 30, 761 (2007)

15. E.R. Collantes, W. Tong, W.J. Welsh and W.L. Zielinski, Anal. Chem., 68, 2038 (1996).

16. K. Heberger, J. Chromatogr. A, 1158, 273 (2007)

17. O. Farkas and K. Heberger, J. Chem. Inf. Model, 45, 339 (2005)

18. A.R. Katritzky, K. Chen, U. Maran and D.A. Carlson, Anal. Chem., 72, $101(2000)$

19. R.P. Adams, Identification of Essential Oil Components by Gas Chromatography/Quadrupole Mass Spectroscopy, Allured Publishing Corp., Carol Stream, IL, USA (2004).
20. L.B. Kier and L.H. Hall, Molecular Connectivity in Structure-Activity Analysis; RSP-Wiley: Chichetster, UK (1986).

21. E.V. Konstantinova, J. Chem. Inf. Comp. Sci., 36, 54 (1997).

22. G. Rucke and C. Rucker, J. Chem. Inf. Comp. Sci., 33, 683 (1993),

23. J. Galvez, R. Garcia, M.T. Salabert and R. Sole, J. Chem. Inf. Comp. Sci., 34, 520 (1994).

24. P. Broto, G. Moreau and C. Vandicke, J. Med. Chem., 19, 66 (1984).

25. N.R. Draper and H. Smith, Applied Regression, Wiley: New York, edn. 2 (1981).

26. M.E. Lucchesi, F. Chemat and J. Smadja, J. Chromatogr. A, 1043, 323 (2004).

27. J.T. Leonardand and K. Ray, Bioorg. Med. Chem., 14, 1039 (2006).

28. M.K. Gupta, R. Sagar, A.K. Shaw and Y.S. Prabhakar, Bioorg. Med. Chem., 13, 343 (2005). 